\title{
DO MARKED TOPICS ENHANCE MEMORY?
}

\author{
HADAR NETZ \\ Ben-Gurion University of the Negev \\ hadar.netz@gmail.com \\ netzh@post.bgu.ac.il \\ ZOHAR EVIATAR \\ University of Haifa \\ zohare@research.haifa.ac.il \\ RON KUZAR \\ University of Haifa \\ kuzar@research.haifa.ac.il
}

\begin{abstract}
We examined the effects of markedness, the deviation from the canonical Subject-VerbObject structure in English, on the memory of listeners for the topic of the sentence. We used three marked topic constructions: Left-Dislocation, Object-Fronting, and SubjectMarking. Sentences with these structures were inserted as the $6^{\text {th }}$ item in lists of 12 canonical sentences. In all sentences the topic was the name of a man. We measured recall of the critical name. The results revealed that topics of Left-Dislocated sentences were recalled more than topics of the other constructions, with topics of Object-Fronting sentences recalled the least. We briefly discuss how sentence processing procedures might give rise to these effects.
\end{abstract}

\section{Introduction}

Marked topics have been shown in linguistic literature to be prominent in discourse (Geluykens 1992, Lambrecht 1994, Prince 1998, Birner and Ward 1998, Gregory and Michaelis 2001, Netz and Kuzar 2007). However, the effect of their prominence on memory has not been explored. It might be suggested that prominence would facilitate memory. Out of this premise, we designed an experiment that would test the effect of marked topic on memory.

Three marked topic constructions have been investigated in this study: Left Dislocation (LD), Object Fronting (OF), and Subject Marking (SM). A detailed description of these constructions appears below.

In Gernsbacher and Shroyer (1989: 536) it is argued that speakers construct their utterances so that listeners will be able to efficiently build mental representations of the discourse. And "One characteristic of an efficient mental representation is that key concepts are easily accessible" (ibid.). Indeed, speakers have been found to use linguistic cues in order to mark important information, and listeners have been found to look for 
these cues in their attempt to make sense of the discourse (Gernsbacher and Hargreaves 1992: 110). Birch and Garnsey (1995: 233) argue that "Focusing on what is most salient may thus be one way that comprehension proceeds in the face of memory limitations. People selectively remember concepts that are perceived as important under the assumption that these salient concepts will be needed later". Similarly, according to Alba and Hasher (1983: 207) the cognitive process of selection is strongly influenced by "the importance effect" according to which the rated importance of ideas affects recall level. Givón (1995: 61) argues: "For the text comprehender, overt grammatical signals syntactic constructions, morphology, intonation - cue the text processor, they guide $\mathrm{it} / \mathrm{him} / \mathrm{her}$ in the construction of a coherent mental representation of the text".

Gernsbacher and Jescheniak (1995: 25), as well as Gernsbacher and Shroyer (1989: 536), have shown that just as speakers use anaphoric devices in order to indicate that a concept has already been mentioned in preceding discourse, speakers also have at their disposal various cataphoric devices, which indicate that a concept is likely to occur again in subsequent discourse. Thus, cataphoric devices are cues for marking salient concepts.

For example, Gernsbacher and Shroyer (1989) argue that the indefinite this functions as a cataphoric cue. In order to test this hypothesis, they presented auditory, constructed narratives to their subjects. The last sentence of each narrative introduced a new concept, either with the indefinite this or with the indefinite a/an. The subjects' task was to continue the narrative. They demonstrate that concepts introduced with this are referred to more frequently, more immediately, and with less explicit anaphors. Therefore they conclude that the indefinite this indeed functions as a cataphoric device, marking concepts as salient. (Gernsbacher and Shroyer 1989: 537-539)

Likewise, Gernsbacher and Jescheniak (1995) have conducted a series of experiments in order to test the accessibility of concepts presented by two cataphoric devices: the indefinite article this and spoken stress. Using a verification task, they showed that when a concept was preceded by the indefinite article this, the concept was more accessible (i.e. verification of target word was more rapid and accurate) than was the same concept preceded by the indefinite article $a / a n$. Next they conducted the same experiment, only this time comparing between stressed vs. unstressed concepts. Again, verification of target words for concepts marked by spoken stress was more rapid and more accurate than was verification of targets for unmarked concepts. Birch and Garnsey (1995) conducted a similar experiment, testing the effect of two types of marked sentences: cleft, and existential sentences (comparing each type of marked sentences to unmarked Subject-Verb-Object sentences) on accessibility of the focused word. They too found that verification of target word was both more rapid and more accurate in the marked sentences.

Taking these various findings into consideration, it makes sense to assume that there are additional cataphoric devices which have not been investigated yet (at least not in this manner). A central premise in the current study is that the marked topic constructions LD, SM and OF function as cues marking important information. This premise has led us to the assumption that recall of the topics of these constructions would be enhanced relative to the recall of the topic of an unmarked sentence.

In English the unmarked sentence has a Subject-Verb-(Object) $(\mathrm{SV}(\mathrm{O}))$ structure, and the subject is not stressed. In the unmarked case the subject is also the topic of the sentence. Deviations from this structure create markedness. The English language 
provides different means of marking the sentence. The sentence can be marked by a morpho-syntactic alternation, as in the case of LD. Consider the following sentence ${ }^{1}$ :

(1) Cathy --

She's not a good friend herself.

In LD the topic (Cathy) is a left-dislocated referent followed by a full sentence, within which there is a resumptive element (she), which refers back to the dislocated topic.

A sentence can also be marked by an order alternation, as in the case of Object Fronting (OF) (a.k.a. Topicalization, Y-Movement), exemplified in the following sentence:

These shoes we never did put on a horse.

In example (2) the sentence begins with the object (these shoes), rather than the subject (we), and thus deviates from the unmarked word order.

Finally, sentences can be marked only prosodically, as in the following sentence:

(3)

.. you know,

has done some of it.

In example (3) the subject (Dad) is stressed and appears in a separate intonation unit from the rest of the sentence. In all other respects, the sentence features the unmarked SVO structure. Following Netz and Kuzar (2007), cases like this are referred to in this paper as Subject Marking (SM).

To conclude, this study was meant to test the hypothesis that marked topics receive special representations in memory, and therefore the recall of these topics should be enhanced. The experiment is based on the paradigm of the Isolation Effect, which was first used by von Restorff (1933), and has since then been replicated in numerous studies (e.g. Jenkins and Postman 1948, Green 1956, Wallace 1965, Schmidt 1991, Hunt 1995, Dunlosky et al. 2000, Hunt and Lamb, 2001). According to the isolation effect, when an isolated item is embedded within a list of homogeneous items, recall of the distinct item is enhanced. For example, a study by Jenkins and Postman (1948) has shown that embedding a meaningful CVC (Consonant-Vowel-Consonant sequence) within a list of meaningless CVCs enhances recall of the isolated item, relative to recall of a homogenous item in the same position in the control list. Similarly, it was hypothesized in the current study that embedding a marked topic construction within a list of unmarked sentences would enhance recall of the marked topic, relative to recall of an unmarked topic in the same position in the control list.

Along with the effect of marked topic on recall, we wanted to check whether marked topics were also perceived as salient. That is, it has been argued that the isolation effect can affect memory even when the isolated items are not perceived as salient. (Hunt

\footnotetext{
${ }^{1}$ Examples 1-3 are taken from the Santa Barbara Corpus of Spoken American English (SBCSAE), Part 1. For the readers' convenience, transcriptions have been slightly simplified.
} 
1995: 110) The empirical test of perceptual salience used here follows the method used by Dunlosky et al. (2000: 650), whereby subjects were asked to make judgments of learning; that is, subjects were asked to answer the question: "How confident are you that in about 10 minutes from now you will be able to recall the item?" (ibid.).

In the following sections, we present the experiment followed by a discussion of its results.

\section{The Experiment}

\subsection{Method}

\subsubsection{Materials}

We constructed a list of 12 sentences. The topics of the 12 sentences are all names of men. In addition, all sentences have transitive verbs, which take direct objects, and all objects are names of women. The following is the full list (in this list, all topics are regular grammatical subjects):

1. Edward confronted Donna.

2. David assisted Karen.

3. Robert interviewed Sharon.

4. Richard bothered Carol.

5. Donald challenged Betty.

6. Thomas found Susan.

7. Daniel trusted Sandra.

8. Kenneth consulted Helen.

9. Michael phoned Lisa.

10. Joseph blamed Nancy.

11. Steven encountered Mary.

12. William inspired Linda.

The names of men and women are taken from frequency lists provided by the US Census Bureau $^{2}$. We took the twelve most frequent names under the condition that they were disyllabic. The order of the proper names is randomized. As for the verbs, we used the frequency list of verbs in WFWSE (Word Frequency in Written and Spoken English) ${ }^{3}$. We did not choose the verbs from the very top of the list because the variance of frequencies at the top of the list was very big. Therefore, we selected the transitive verbs from a range of 110 verbs above and below the median. In addition, in our selection of verbs we have decided not to include verbs that have a dramatic or highly emotional content, such as capture or bury. Hence, we ended up with verbs within a frequency

\footnotetext{
${ }^{2}$ See http://www.census.gov/genealogy/names/names_files.html

${ }^{3}$ See http://www.comp.lancs.ac.uk/ucrel/bncfreq/flists.html
} 
range of 23 to 44 (per million verbs). Like the proper names, the verbs have also been randomized.

The list had four versions: three experimental lists, and one control list. In the control list, all 12 sentences, including the sentence in $6^{\text {th }}$ serial position, were unmarked SVO (as in the list above). In the three experimental lists, all sentences were unmarked SVO, except the sentence in $6^{\text {th }}$ serial position, which was marked. In List A, the marked sentence was an LD, in List B an SM, and in List C an OF. Here is the unmarked SVO sentence in $6^{\text {th }}$ serial position:

Thomas found Susan. ${ }^{4}$

Its LD counterpart in List A:

Thomas,

he found Susan.

Its SM counterpart in List B:

Thomas, found Susan.

Finally, its OF counterpart in List C:

Thomas,

Susan found.

The sentences were recorded and saved as audio files. In the recording process, the sentences were read by a native speaker of English. The intonation pattern was controlled, and made to abide by the intended pattern, whereby the control, prosodically unmarked sentences occupied a single intonation unit, whereas the three marked sentences consisted of two intonation units, one for the topic and another for the rest of the sentence. During the experiment itself, the sentences were played on a CD player.

\subsubsection{Subjects}

The subjects in the experiment were 129 students from the Rothberg International School of the Hebrew University of Jerusalem, ages 18-23, all native speakers of North American English. The subjects were divided into four groups. Consequently, three groups (unmarked SVO, LD and SM) were made up of 32 people, and the fourth group (OF) of 33 .

\footnotetext{
${ }^{4}$ In this and the following three examples, each line represents a separate intonation unit. Thus, in the unmarked case the whole sentence constituted a single intonation unit, whereas in the three marked sentences, the topic appeared in a separate intonation unit from the rest of the sentence. Features that characterize delimitation of an intonation unit include changes in aspects such as pitch, duration, intensity and voice quality, as well as pauses (Chafe 1994: 58). The intonation of the test sentences was made to abide by these characteristics.
} 


\subsubsection{Procedure}

The experiment consisted of a single study-test trial. During the study trial one of the four lists of sentences was presented auditorily. The subjects were informed in advance that their task was to remember the names of the men that appeared in the sentences ${ }^{5}$. Immediately after the offset of the presentation of each sentence in the list, a judgment of learning was made for that item. The judgments of learning were made individually, on a sheet provided before the beginning of the trial, and were based on the query "How confident are you that in about 10 minutes from now you will be able to recall the name of the man in each of the sentences?" $(0=$ definitely will not recall; $10=10 \%$ sure; $20=$ $20 \%$ sure, $30=30 \%$ sure; $40=40 \%$ sure; $\ldots 100=$ definitely will recall). After the 12 sentences had been studied and judged, the subjects were given a ten-minute distractor task of solving two mini-Sudoku puzzles. Finally, subjects were given as much time as they wanted to recall on a piece of paper as many names of men as possible (the subjects were told in advance that order did not matter).

\subsection{Results and discussion}

The following table presents the absolute numbers and the proportions of recall for the critical item (i.e. the topic of sentence no. 6: Thomas) separately for each of the four groups:

\begin{tabular}{|l|l|l||l|}
\hline Group (Sentence Type) & $\begin{array}{l}\text { Successful } \\
\text { Recall of \# 6 }\end{array}$ & Unsuccessful Recall of \# 6 & Total \\
\hline $\begin{array}{l}\text { Unmarked SVO (Control) } \\
\text { \% within group }\end{array}$ & 18 & 14 & 32 \\
\hline LD & $56.25 \%$ & $43.75 \%$ & $100 \%$ \\
\% within group & 23 & 9 & 32 \\
\hline SM & $71.88 \%$ & $28.12 \%$ & $100 \%$ \\
\% within group & 14 & 18 & 32 \\
\hline OF & $43.75 \%$ & $56.25 \%$ & $100 \%$ \\
\% within group & 12 & 21 & 33 \\
\hline \hline Total & $36.36 \%$ & $63.64 \%$ & $100 \%$ \\
\% within group & 67 & 62 & 129 \\
\hline & $51.94 \%$ & $48.06 \%$ & $100 \%$ \\
\hline
\end{tabular}

Table 1: Recall of Critical Item

As we can see from the table, recall was greatest for the topic of the LD construction (.72). In addition, we see that recall of the topic of the unmarked SVO sentence (.56) was

\footnotetext{
5 The experiment was meant to test the hypothesis that marked topics are salient and therefore remembered better than are unmarked topics. Thus, since we were specifically interested in the salience of the topic, the experiment included an intentional memory task: the subjects were explicitly instructed to remember the sentence topics (rather than the whole sentence or all names, including women's, etc.).
} 
greater than was recall of the topic of the marked SM construction (.44). Furthermore, recall of the topic of the unmarked SVO sentence was also greater than was recall of the topic of the marked OF construction (.36). Consistent with these observations, Chisquare revealed that the effect of sentence type on recall of the topic of the sentence was significant $\left(\chi_{(3)}^{2}=9.4 ; \mathrm{p}<.05\right)$. In other words, we can reliably conclude that the observed difference in recall resulted from the difference in sentence structure.

Post-hoc comparisons indicate that the observed differences in recall between each of the isolated items (LD, SM and OF), and the homogenous item (unmarked SVO) actually did not reach significance (in LD vs. unmarked SVO: $\chi_{(1)}^{2}=1.69 ; \mathrm{p}>.05$; in SM vs. unmarked SVO: $\chi_{(1)}^{2}=1 ; \mathrm{p}>.05$; in OF vs. unmarked SVO: $\chi_{(1)}^{2}=2.54 ; \mathrm{p}>$ $.05)$. However, significant results were obtained both in the difference between LD and $\mathrm{SM}\left(\chi_{(1)}^{2}=5.18 ; \mathrm{p}<.05\right)$, as well as in the difference between $\operatorname{LD}$ and $\mathrm{OF}\left(\chi_{(1)}^{2}=8.32\right.$; $\mathrm{p}<.05)$.

Directly related to this issue, it is interesting to look now also at the results of the judgments of learning, in order to check whether the isolated items were perceived as salient. Table 2 presents the mean and the standard deviation of the judgments of learning (JOL) of the critical item (i.e. the topic of sentence no. 6) relative to the mean and the standard deviation of the judgments of learning of the immediately preceding item (i.e. the topic of sentence no. 5) in each of the four lists.

\begin{tabular}{|l|l|l|l|l|l|l|}
\hline & \multicolumn{2}{|l|}{$\begin{array}{l}\text { Comparison Item } \\
\text { No.5 }\end{array}$} & \multicolumn{2}{l|}{$\begin{array}{l}\text { Nritical Item } \\
\text { No.6 }\end{array}$} & & \\
\hline Sentence Type & Mean JOL & Std. Deviation & Mean JOL & Std. Deviation & T & Sig \\
\hline Unmarked SVO (Ctrl) & 54.7 & 20.5 & 51.3 & 25.1 & .92 & $\mathrm{p}>.05$ \\
\hline LD & 56.9 & 24.7 & 47.2 & 27.1 & 2.17 & $\mathrm{p}<.05$ \\
\hline SM & 52.2 & 27.4 & 50.9 & 25.4 & .43 & $\mathrm{p}>.05$ \\
\hline OF & 47.3 & 21.7 & 48.2 & 24.9 & -.19 & $\mathrm{p}>.05$ \\
\hline
\end{tabular}

Table 2: Judgments of Learning

As we can see from the table, in three of the four groups (unmarked SVO, SM, and OF), the mean JOL of the critical item was not significantly different from the mean JOL of the comparison item. Only in LD, a significant difference was in fact observed but note that the difference was in the opposite direction from the expectation. Thus, in LD the comparison item (no. 5) was in fact judged as even more salient than was the critical item (no. 6).

It is perhaps not so surprising that the marked topics were not perceived as salient. First, numerous studies dealing with sentence recall have shown that comprehenders typically code and remember the content, but NOT the form of recently comprehended information (Alba and Hasher 1983: 208, Gernsbacher 1990: 72). Secondly, as Eysenck and Keane (2005: 538) point out: "we are only consciously aware of a small fraction of the information processing going on in our brain at any given moment". According to Baars and Franklin (2003), the conscious contents of the working memory often involve inner speech and reportable goals. In the current experiment, the conscious contents of the working memory were most probably the names of the men from the sentences, since the task at hand was to remember these names. Therefore, it actually makes sense that changes in sentence structure went by unnoticed. Still, it is interesting that despite the 
unawareness of structure, precisely structure has been found to have a significant effect on memory.

We would like to elaborate now on the effect that structure has had on memory. As pointed out earlier, our initial expectation that markedness would lead to better recall has not been confirmed. That is, recall of none of the marked topics was significantly greater than was recall of the unmarked topic. Interestingly, similar results have been recently reported in a study by Almor and Eimas (2008). In their experiments, they checked both lexical decisions and recall of focused referents in focus constructions (it-cleft and whcleft). They found facilitated referent identification (i.e. facilitation of on-line processing), but no (or even adverse) effect on recall of the focused referent (i.e. no facilitation of encoding in long term memory). They conclude that "while focus may affect the local processing and interpretation of discourse, it does not normally leave any trace in the resulting memory representation" (Almor and Eimas 2008: 221-222).

In addition, as pointed out by Almor and Eimas (2008: 221), although their findings seem to conflict with Birch and Garnsey's (1995) findings, it is important to note that that the latter researchers looked at referent identification, whereas the former checked both referent identification and recall. Thus, while focalization facilitates on-line processing, it does not facilitate recall. Our results, then, resemble Almor and Eimas's, except that we examined topic constructions whereas they looked at focus constructions. Just as they found no positive effect of focalization on recall of the focused referent, so have we not found any positive effect of topicalization on recall of the topic referent.

Furthermore, Almor and Eimas (2008: 222) found that focus might have an adverse effect on memory "under conditions which are not typical of regular discourse", namely in cleft sentences involving full lexical repetition (It was the bird that ate the fruit. The bird seemed very satisfied). They suggest that full lexical repetition, which is unnatural in discourse, creates "a costly expression" that "interferes with encoding in long-term memory and therefore leads to poorer representation of the discourse in long-term memory" (Almor and Eimas 2008: 204).

This takes us back to the significant difference in recall that we found between different topic constructions. As noted above (Table 1 and discussion), post-hoc comparisons indicate that recall of the topic of LD (.72) was significantly better than recall of the topics of SM (.44) and OF (.36). The interference of the full lexical repetition with long-term encoding found in Almor and Eimas (2008) is analogous to the poor recall of the topic referent of OF found in our study. Like full lexical repetition, OF also constitutes a costly expression. Here are some possible reasons for the high cost of OF.

According to Bever and Townsend (2001: 151), the initial stage of sentence perception involves only crude semantic and syntactic recognition. Within this first stage, the initial syntactic perception is based on "canonical syntactic patterns" (ibid.). Furthermore, Jansma, Ramsey, Slagter, and Kahn (2001) found that automatic processing was associated with reduced usage of working memory. In contrast, in the current experiment, in the case of $\mathrm{OF}$, it seems that automatic sentence parsing was disrupted, bringing about a cognitive load on working memory, which consequently inhibited recall of the topic. Indeed, it has been shown (Schlesewsky et al. 2000) that comprehenders tend towards a subject first interpretation of initial NPs. In other words, the fronted object is initially, and perhaps automatically (Eysenck and Keane 2005: 179) 
misconstrued as the subject of the sentence. "If, however, the object interpretation becomes necessary [...], a reanalysis of the input should be required including a complex recomputation of the syntactic representation of the object first reading" (Bahlmann et al. 2007). Clearly, such complex recomputation would take its cognitive toll.

Similarly, Gibson (1998) discusses the memory costs of online sentence processing. He argues that NPs awaiting the assignment of a thematic role demand a cost on working memory. Schlesewsky et al. (2000) make the same claim specifically with regard to initial objects. In other words, while in sentences that have an SVO word order there is a single referent prior to the predicate, in sentences with an OSV word order there are two referents awaiting assignment of a thematic role, causing a cognitive load, which inhibits rather than facilitates recall of the topic.

$\mathrm{OF}$, then, has been shown to be a costly expression. Less so was the case of LD. Almor and Eimas (2008) indeed found an adverse effect only in the case of unnatural discourse. We would like to point out that relative to OF, LD is unnatural to a lesser extent. Indeed, if we look at the distribution of the two constructions in discourse, we see that $\mathrm{OF}$ is much less frequent in discourse, and thus much more unnatural than is LD. Altogether, only 34 occurrences of OF were found in the SBCSAE, Parts 1-4, in contrast to 207 occurrences of LD. Hence the use of LD is lexically stronger, i.e. more entrenched, than is the use of OF (for further discussion of "lexical strength"/ "entrenchment" see Bybee, 1985: 117, and Langacker, 1987: 59, respectively).

Netz and Kuzar (2010) have conducted an equivalent experiment of the same marked topic constructions in Hebrew. Like English, Hebrew is also an SVO language. However, as Netz and Kuzar (2010) point out, in Hebrew in the fronting of a definite direct object (e.g. et Tomer, Shoshi matz'a [Tomer, Shoshi found]), the fronted object is marked by the accusative case marker et. Thus, unlike in English, in Hebrew OF is not misconstrued as SVO, and therefore the recomputation process required in English OF is not required in Hebrew. And indeed, Netz and Kuzar (2010) have found that in Hebrew, in contrast to English, there is no difference in recall between the topics of LD and OF.

We would like to go back now to the discussion of the significant difference observed in English between LD on the one hand, and OF and SM on the other. It seems that in the case of LD, there are several factors which alleviate, rather than aggravate, the cognitive load. To start with, LD involves the use of a resumptive pronoun. Pronouns have been found to facilitate on-line processing (Chang 1980, and see Macdonald's 1989: 35-36 example: John went to the store, and he talked to the cashiers versus John went to the store and the cashiers were friendly. "The pronoun he primes its antecedent John"). Likewise, Fodor and Garrett (1967: 290) show that embedded sentences with a relative pronoun (The man whom the dog bit died) are perceptually less complex than are equivalent sentences in which the relative pronoun has been deleted (The man the dog bit died). According to Fodor and Garrett (ibid.) the existence of a relative pronoun facilitates subjects in working out the grammatical relations of the sentence. We would like to argue that in LD, very much like in other constructions containing pronouns (Chang 1980, Macdonald 1989, Fodor and Garrett 1967), the resumptive pronoun facilitates cognitive processing, and therefore LD is significantly less costly than are SM and $\mathrm{OF}$.

Furthermore, Prince (1998: 286), in her definition of "Simplifying LDs" and Lambrecht (1994: 185), in his definition of the "Principle of Separation of Reference and 
Role" have indeed argued that LD facilitates cognitive processing by allowing a separation between the introduction of a referent and the expression of a proposition about this referent (a line of thinking that was earlier pointed out - not in explicit relation to LD - by Du Bois (1980: 273 and 1987: 830-832)). However, neither Prince nor Lambrecht have offered empirical evidence for this claim. It seems that the results of the current experiment offer the necessary reinforcement. The results of the experiment indicate that in contrast to $\mathrm{OF}$ and SM, in which the referent and the proposition are expressed in a single clause, $\mathrm{LD}$, which allows "separation of reference and role", indeed facilitates recall of its topic.

To conclude, the results of the experiment presented here are intriguing. The results indicate that, in contrast to expectations, marked sentence structure does not necessarily have a facilitative effect on recall. We have suggested that in OF, the distinct OSV word order has created a cognitive load. In contrast, we have argued that in LD, the existence of a resumptive pronoun as well as the separation of reference and role have alleviated the cognitive load. In the competition between alternative motivations, then, the overall effect of facilitative factors on memory is strong enough in LD to override the inhibitive effects, whereas in OF and SM the power relations are reversed.

This ties in with Gernsbacher's Structure Building Framework and the concept of the "advantage of first mention". According to the Structure Building Framework, "during the beginning of sentences, clauses, and phrases, mental foundations are being laid" (Gernsbacher and Hargreaves 1992: 87-88). These foundations enjoy an advantage of first mention (Gernsbacher and Hargreaves 1992, Carreiras et al. 1995). Our findings introduce a gradient into the domain of first mention, whereby it seems that not all foundations are equally privileged. The topic of LD constitutes a more solid foundation than do the topics of SM and OF, hence its better recall.

\section{Conclusion}

This research serves as evidence that despite the process of abstraction, whereby structure is lost and only meaning gets coded, the short stage of sentence perception prior to abstraction nevertheless bears a significant effect on people's memory. Interestingly, the effect is not as straightforward as one would expect. Thus, the results of the experiment indicate that marked sentence structure does not necessarily have a facilitative effect on memory. Instead, the resulting model defines a state of competition between facilitative and inhibitive factors, and offers explanations for the different balance of power in each of the three cases of marked constructions.

\section{References}

Alba, J. W. and L. Hasher. 1983. Is memory schematic? Psychological Bulletin 93(2): 203-231.

Almor, A. and P. D. Eimas. 2008. Focus on noun phrase anaphors in spoken language comprehension. Language and Cognitive Processes 23(2): 201-225. 
Baars, B. J. and S. Franklin. 2003. How conscious experience and working memory interact. TRENDS in Cognitive Sciences 7(4): 166-172.

Bahlmann, J., A. Rodriguez-Fornells, M. Rotte and T. F. Münte. 2007. An fMRI study of canonical and noncanonical word order in German. Human Brain Mapping 28: 940-949.

Bever, T. G. and D. J. Townsend. 2001. Some sentences on our consciousness of sentences. In E. Dupoux (ed) Language, Brain, and Cognitive Development: Essays in Honor of Jacques Mehler. Cambridge, Mass.: MIT Press: 143-155.

Birch, Stacy L. and Susan M. Garnsey. 1995. The effect of focus on memory for words in sentences. Journal of Memory and Language 34: 232-267.

Birner, B. J. and G. L. Ward. 1998. Information Status and Noncanonical Word Order in English. Amsterdam: John Benjamins.

Bybee, J. 1985. Morphology: A study of the Relation between Meaning and Form. Amsterdam and Philadelphia: John Benjamins.

Carreiras, M., M. A. Gernsbacher and V. Villa. 1995. The advantage of first mention in Spanish. Psychonomic Bulletin \& Review 2(1): 124-129.

Chafe, W. 1994. Discourse, Consciousness and Time: The Flow and Displacement of Conscious Experience in Speaking and Writing. Chicago: The University of Chicago Press.

Chang, F. R. 1980. Active memory processes in visual sentence comprehension: Clause effects and pronominal reference. Memory \& Cognition 8(1): 58-64.

Du Bois, J. W. 1980. Beyond definiteness: The trace of identity in discourse. In W. Chafe (ed) The Pear Stories: Cognitive, Cultural and Linguistic Aspects of Narrative Production. Norwood, NJ: Ablex: 203-274.

Du Bois, J. W. 1987. The discourse basis of ergativity. Language 63(4): 805-855.

Du Bois, J. W. 2000. Santa Barbara corpus of spoken American English, Parts 1, 2, 3 \& 4. Philadelphia: Linguistic Data Consortium, University of Pennsylvania.

Dunlosky, J. R., R. R. Hunt and E. Clark. 2000. Is perceptual salience needed in explanation of the isolation effect? Journal of Experimental Psychology: Learning, Memory, \& Cognition 26(3): 649-657.

Eysenck, M. W. and M. T. Keane. 2005. Cognitive Psychology: A Student's Handbook, 5 th edition. New York: Psychology Press.

Fodor, J. A. and M. Garrett. 1967. Some syntactic determinants of sentential complexity. Perception \& Psychophysics 2(7): 289-296.

Geluykens, R. 1992. From Discourse Process to Grammatical Construction: On LeftDislocation in English. Amsterdam and Philadelphia: John Benjamins.

Gernsbacher, M. A. 1990. Language Comprehension as Structure Building. Hillsdale, NJ: Lawrence Erlbaum Associates.

Gernsbacher, M. A. and D. J. Hargreaves. 1992. The privilege of primacy: Experimental data and cognitive explanations. In D. L. Payne (ed) Pragmatics of Word Order Flexibility. Amsterdam/Philadelphia: John Benjamins: 83-116.

Gernsbacher, M. A. and J. D. Jescheniak. 1995. Cataphoric devices in spoken discourse. Cognitive Psychology 29: 24-58.

Gernsbacher, M. A. and S. Shroyer. 1989. The cataphoric use of the indefinite this in spoken narratives. Memory \& Cognition 17: 536-540. 
Gibson, E. 1998. Linguistic complexity: locality of syntactic dependencies. Cognition 68: 1-76.Givón, T. 1995. Coherence in text vs. coherence in mind. In M. A. Gernsbacher and T. Givón (eds) Coherence in Spontaneous Text. Amsterdam: John Benjamins: 59-115.

Green, R.T. 1956. Surprise as a factor in the von Restorff Effect. Journal of Experimental Psychology 52(5): 340-344.

Gregory, M. L. and L. A. Michaelis. 2001. Topicalization and left-dislocation: A functional opposition revisited. Journal of Pragmatics 33(11): 1665-1706.

Hunt, R. R. 1995. The subtlety of distinctiveness: What von Restorff really did. Psychonomic Bulletin \& Review 2(1): 105-112.

Hunt, R. R. and C. A. Lamb. 2001. What causes the isolation effect? Journal of Experimental Psychology: Learning, Memory, and Cognition 27(6): 1359-1366.

Jansma, J. M., N. F. Ramsey, H. A. Slagter and R. S. Kahn. 2001. Functional anatomical correlates of controlled and automatic processing. Journal of Cognitive Neuroscience 13: 730-743. Jenkins, W. O. and L. Postman. 1948. Isolation and 'spread effect' in serial learning. American Journal of Psychology 61: 214-221. Lambrecht, K. 1994. Information Structure and Sentence Form. Cambridge: Cambridge University Press.

Langacker, R. W. 1987. Foundations of Cognitive Grammar, Volume 1: Theoretical Prerequisites. Stanford, CA: Stanford University Press.

MacDonald, M. C. 1989. Priming effects from gaps to antecedents. Language \& Cognitive Processes 4(1): 35-56.

Netz, H. and R. Kuzar. 2007. Three marked theme constructions in spoken English. Journal of Pragmatics 39(2): 305-335.

Netz, H. and R. Kuzar. 2010. Three effect of marked topic on memory in Hebrew and English. Languages in Contrast 9(2): 267-283.

Prince, E. F. 1998. On the limits of syntax, with reference to Left-Dislocation and Topicalization. In P. W. Culicover and L. McNally (eds) Syntax and Semantics 29, The Limits of Syntax. New York: Academic Press: 281-302.

Schlesewsky, M., G. Fanselow, R. Kliegl and J. Krems. 2000. The subject preference in the processing of locally ambiguous wh-questions in German. In B. Hemforth and L. Konieczny (eds) German Sentence Processing. Dordrecht: Kluwer: 65-94.

Schmidt, S. R. 1991. Can we have a distinctive theory of memory? Memory \& Cognition 19(6): 523-542.

von Restorff, H.1933. Über die wirkung von bereichsbildungen im spurenfeld / The effects of field formation in the trace field. Psychologische Forschung 18: 299-342.

Wallace, W. P. 1965. Review of the historical, empirical, and theoretical status of the von Restorff phenomenon. Psychological Bulletin 63(6): 410-424.

Wright, S. and T. Givón. 1987. The pragmatics of indefinite reference: Quantified textbased studies. Studies in Language 11: 1-33. 


\section{About the Authors}

Hadar Netz has recently completed a Fulbright Post-Doctoral Fellowship in the Center for Gifted Education, the College of William \& Mary, Williamsburg, VA. She is currently a Kreitman Post-Doctoral Fellow at the Department of Education, Ben-Gurion University, Beer-Sheva, Israel. Her research focuses on the classroom discourse of gifted pupils. Her additional research interests include information structure, discourse analysis, and psycholinguistics.

Zohar Eviatar is Associate Professor at the Department of Psychology, the University of Haifa, Israel. She is interested in hemispheric asymmetry for higher cognitive functions with a focus on reading in different languages, and hemispheric functioning in clinical groups with social and linguistic pathology such as Williams syndrome, autism, and nonverbal learning disabilities.

Ron Kuzar is Senior Lecturer at the Department of English Language and Literature, the University of Haifa, Israel. His research interests include cognitive linguistic theory, syntax, information structure, and the linguistic encoding of cultural and political ideologies. 